This item was submitted to Loughborough's Research Repository by the author.

Items in Figshare are protected by copyright, with all rights reserved, unless otherwise indicated.

\title{
Using a single uniaxial gyroscope to detect lateral ankle sprain hazard
}

PLEASE CITE THE PUBLISHED VERSION

https://doi.org/10.1109/JSEN.2020.3021855

\section{PUBLISHER}

Institute of Electrical and Electronics Engineers (IEEE)

\section{VERSION}

AM (Accepted Manuscript)

\section{PUBLISHER STATEMENT}

(c) 2020 IEEE. Personal use of this material is permitted. Permission from IEEE must be obtained for all other uses, in any current or future media, including reprinting/republishing this material for advertising or promotional purposes, creating new collective works, for resale or redistribution to servers or lists, or reuse of any copyrighted component of this work in other works.

\section{LICENCE}

All Rights Reserved

\section{REPOSITORY RECORD}

Fong, Daniel, Yue-Yan Chan, Vikki Chu, Alan Lam, and Patrick Yung. 2020. "Using a Single Uniaxial Gyroscope to Detect Lateral Ankle Sprain Hazard". Loughborough University. https://hdl.handle.net/2134/12901340.v1. 


\title{
Using a single uniaxial gyroscope to detect lateral ankle sprain hazard
}

\author{
Daniel T.P. Fong, Yue-Yan Chan, Vikki W.S. Chu, Alan H.F. Lam, Member, IEEE, Patrick S.H. Yung
}

\begin{abstract}
Lateral ankle sprain is very common in sports. Recently, there was a wearable assistive technology that stimulates the peroneal muscles to prevent this injury, but it requires a monitoring system to detect injury hazards and actuate the protection. This study presents the feasibility of a uniaxial gyroscope to monitor the peak ankle inversion velocity during common sporting motion and simulated ankle sprain motion. Ten males performed walking, running, 45-deg cutting, vertical jump-landing, stepping-down from a block, 5 kinds of simulated ankle sprain motion on sprain simulators, and a manual ankle-twisting motion in a biomechanics laboratory. The peak ankle inversion velocity was collected by an optical motion analysis system at $120 \mathrm{~Hz}$. Besides, a uniaxial gyroscope was attached to the heel to collect the peak twisting velocity at $500 \mathrm{~Hz}$. Pearson test showed a strong or high positive correlation between the two parameters. Independent t-test showed no difference

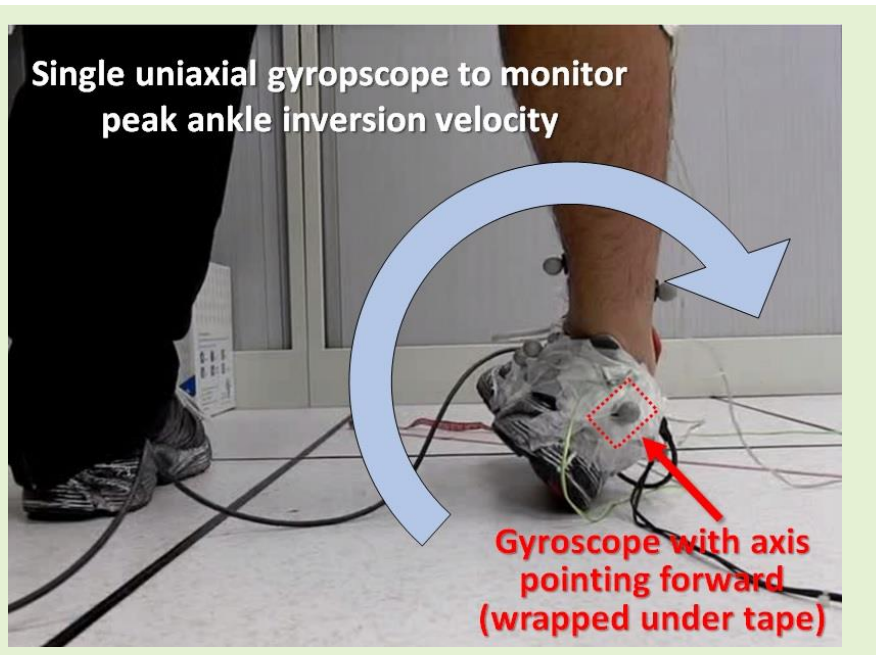
between the two parameters in all testing motions except the manual ankle-twisting test which the value was $82 \%$ of that from the optical motion capture system and both values are above the threshold, $300 \mathrm{deg} / \mathrm{s}$. We concluded the method is applicable to detect the hazard of lateral ankle sprain injury.
\end{abstract}

Index Terms_-Angular rate sensors, ankle sprain, biomechanics, gyroscope, injury prevention, medical application, motion sensing, sensor application, sensor telemetry and monitoring, sensor testing and evaluation, sports medicine

\section{INTRODUCTION}

$\mathrm{L}$ ATERAL ankle sprain is very common in sports $[1,2]$. Inadequate treatment after repeated lateral ankle sprains may lead to chronic ankle instability [3], which may further

Manuscript received August 5, 2020; accepted September 1, 2020. Date of publication MM DD, YYYY; date of current version MM DD, YYYY. This work was supported by equipment and resources donated by The Hong Kong Jockey Club Charities Trust and The Innovation Technology Fund from the Innovation and Technology Commission, Hong Kong Special Administrative Region Government (ITS/013/07). The associate editor coordinating the review of this article and approving it for publication was Dr. Kazuaki Sawada. (Corresponding author: Patrick S.H. Yung)

Daniel T.P. Fong is with the National Centre for Sport and Exercise Medicine, School of Sport, Exercise and Health Sciences, Loughborough University, Loughborough, LE113TU UK (e-mail: d.t.fong@lboro.ac.uk).

Yue-Yan Chan is with the Scientific Conditioning Centre, Elite Training Science \& Technology Division, Hong Kong Sports Institute, Hong Kong, China (e-mail: cyy@hksi.org.hk).

Vikki W.S. Chu is with the Department of Orthopaedics and Traumatology, Prince of Wales Hospital, Faculty of Medicine, The Chinese University of Hong Kong, Hong Kong, China (e-mail: vikkichu@ort.cuhk.edu.hk).

Alan H.F. Lam is with the Department of Electrical Engineering, College of Engineering, City University of Hong Kong, Hong Kong, China (e-mail: hiuflam@cityu.edu.hk).

Patrick S.H. Yung is with the Department of Orthopaedics and Traumatology, Prince of Wales Hospital, Faculty of Medicine, The Chinese University of Hong Kong, Hong Kong, China (e-mail: patrickyung@cuhk.edu.hk). cause lower leg stiffness [4], greater variation in lower extremity joint coupling [5], post-traumatic osteoarthritis [6], and may further require surgical stabilisation [7] or even total ankle replacement surgery [8]. Preventing ankle sprain injury has been suggested in one of the eight recommendations for future research by the International Ankle Consortium [9], and there are different attempts such as the use of ankle taping [1012], bracing [13], and exercise interventions [14].

Delayed peroneal muscle reaction time has been proposed as an aetiology of lateral ankle sprain injury, as this delay may cause the ankle evertors to fail to contract in time to stop excessive ankle inversion motion $[15,16]$. There were different attempts to aim to reduce such delay by cryotherapy and ankle bracing [17], plyometric training [18], and neuromuscular training [19]. Recently, there was a wearable assistive technology which delivers external electrical stimulation through the skin surface to the peroneal muscles to activate the muscles before they could react [20-22]. Its effect has been demonstrated to be effective in resisting simulated ankle sprain motion in biomechanics laboratory trials [23,24]. However, the success of the abovementioned device depends on if an injury hazard can be detected, to actuate the correction system in time to stop the injurious motion. One option is to monitor the strain in, or elongation of, the lateral ankle ligaments using differential variable reluctance transducer [25]. However, this requires surgical procedure the implant the 
transducer into the ligament and is therefore not practical for general sportsmen. Another option is to devise a wearable system to monitor the ankle joint supination torque [26], however, there is no study on how much torque would start to tear the lateral ankle ligaments in living humans, and therefore a threshold to determine the actuation of the correction system cannot be established.

A possible option is to monitor the foot and ankle kinematics with the use of wearable inertial motion sensors [27], which has been used in wireless motion sensing in sports science applications [28]. O'Donovan and colleagues [29] devised a method that uses two motion sensors attached to the shank and foot segments to measure the 3D inter-segment ankle joint angle, but the method was yet limited to a static but not a dynamic environment. Chan and colleagues [30] used one motion sensor attached to the calcaneus to identify simulated ankle sprain motion with a support vector machine (SVM) method, but the method required data collection of one second plus additional time for processing the complete 3D linear accelerometry and gyrometry data from the motion sensor. Previous studies suggested that an ankle sprain injury occurred in 40-50 ms after foot strike [15,31] and the delay from the peroneal muscle stimulation to the generated ankle pronation torque was within 21-25 $\mathrm{ms}$ [32]. Therefore, the ankle sprain injury hazard must be detected within 19-25 ms after it has started occurring, and these two methods were yet to be feasible for real-time ankle sprain identification.

As a series of lateral ankle sprain case reports reported that the peak ankle inversion velocities were all very high, ranging from 481 to $1752 \mathrm{deg} / \mathrm{s}$ [33-36], Chu and colleagues [37] proposed $300 \mathrm{deg} / \mathrm{s}$ to be a threshold to differentiate these ankle sprain motions and common sporting motions which were with the peak inversion velocities below about $200 \mathrm{deg} / \mathrm{s}$. We believed that by using a fast-sampling uniaxial gyroscope attached at the heel, we can monitor the peak inversion velocity and therefore the hazard of a lateral ankle sprain. In this study, the peak twisting velocity recorded during various sporting motions and simulated ankle sprain motions by a uniaxial gyroscope were compared to the peak ankle inversion velocity recorded by a golden-standard motion capture system. We hypothesised that there is a positive linear relationship and no significant difference between the two parameters.

\section{MethODS}

\section{A. Participants}

Ten recreational male athletes (age $=23.4 \pm 3.0$ years, height $=1.73 \pm 0.03 \mathrm{~m}$, body mass $=65.1 \pm 9.7 \mathrm{~kg}$ ) participated in this study. A previous study on usability engineering suggested that 5 participants are already adequate, and not much additional value will be obtained beyond 10 [38]. Therefore, in this study, 10 participants were recruited. Written informed consent was obtained from all participants and the university ethics committee approved the study. Only male participants were recruited as to avoid any potential sex difference in ankle joint kinematics, and to allow us to recruit participants with the same shoe size (Europe 40) to fit the size of the testing show equipped with the motion sensor. All participants were athletes who participate in at least one kind of court sports which sideward or cutting movements are commonly present, such as basketball, football, handball, etc, at the recreational level.

\section{B. Equipment}

Each participant wore the same pair of cloth sports shoes [39] provided by the research team (shoe size $=$ Europe 40) with a wearable inertial motion sensor (Sengital Ltd, Hong Kong, China) attached to the heel counter, with one rotational axis aligned to the longitudinal axis of the foot segment. The gyroscope was firmly attached to the shoe by tape to minimise the motion artefact between the sensor and the shoe (Figure 1a). The size of the motion sensor was $20 \times 18 \times 6 \mathrm{~mm}^{3}$, and it consisted of a tri-axial accelerometer collecting threedimensional linear acceleration, and a tri-axial gyrometer collecting three-dimensional angular velocity with a sampling frequency of $500 \mathrm{~Hz}$ [30].

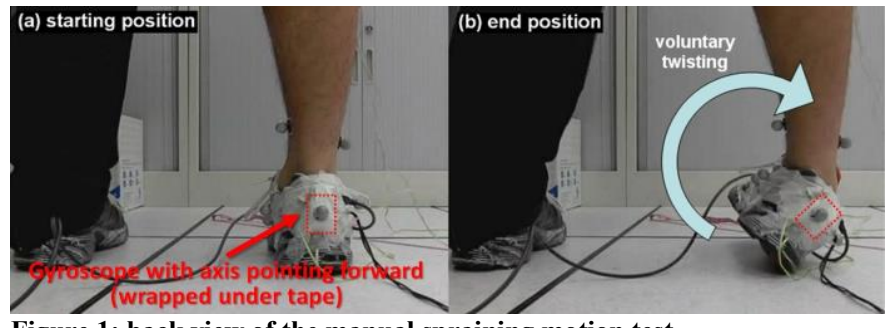

Figure 1: back view of the manual spraining motion test

The working principle of the motion sensor is to first measure the change of linear acceleration along three orthogonal axes, then calculate the angular orientation of the object. The motion sensor has a working range of $\pm 2 \mathrm{~g}$, resolution of $5 \mathrm{mg}$, bandwidth of $5000 \mathrm{~Hz}$, working temperate range of $0-70{ }^{\circ} \mathrm{C}$, and a mean error of measuring the angular orientation of 0.4551 degrees. It is highly accurate with very good sensitivity for sports science applications with human participants [28]. The angular velocity along the rotational axis aligned to the longitudinal axis of the foot segment was collected by a computer and extracted to represent the ankle joint inversion velocity. It was the rotation about this single axis but not a combination of the 3 axes.

Twelve reflective markers ( $5 \mathrm{~mm}$ diameter) were attached to lateral fibula epicondyle, tibial tuberosity, lateral proximal shank, medial proximal shank, anterior distal shank, lateral distal shank, medial distal shank, posterior heel, lateral heel, medial heel, medial foot, and dorsal foot. Marker coordinates were recorded by an optical motion analysis system (VICON, UK) at $120 \mathrm{~Hz}$. The two systems were synchronised by connecting the gyroscope system to the VICON motion analysis system which collected the data simultaneously.

\section{Data processing}

The marker coordinates were filtered by the Generalized Cross-Validation package of Woltring with $15 \mathrm{~Hz}$ cut-off frequency [40]. A static calibration trial with the participant standing in the anatomical position served as the offset position to determine the segment embedded axes of the shank and foot segment. The foot and shank segments were embedded with the Laboratory Coordinate System (LCS). A singular value decomposition method was employed to 
calculate the transformation from the triad reference frame to the anatomical shank and foot reference frame [41]. Joint kinematics was deduced by the Joint Coordinate System (JCS) method [42]. Ankle inversion angle was defined as the angle between the shank sagittal plane directional axis and foot sagittal plane directional axis. Its velocity was the change concerning time and was collected and batch-processed by a customised Matlab program.

The raw data from the gyropscope was directly extracted and trimmed to obtain the peak ankle inversion velocity. Filter has been commonly used to smooth motion sensor data [43], however, our previous study showed that the raw ankle inversion kinematics data recorded by the same motion sensor showed no change after being filtered with a $20 \mathrm{~Hz}$ Butterworth low pass filter [30]. Besides, since a filter after data collection would make the device impractical for realtime detection of ankle sprain hazard, we decided to not filter and use the raw data directly from the gyroscope.

\section{Experimental protocol}

Each participant performed ten trials of walking and running on a $10-\mathrm{m}$ walking path at his natural cadence [44], 45-deg forward and sideward cutting movement [39], and vertical jump-landing and a stepping-down from a block motion [37] on a force plate (Advanced Mechanical Technology Inc., USA) in a random sequence in a motion biomechanics laboratory. These motions were chosen because they are common in various kinds of sports [30,37]. Each participant also performed three trials of a series of simulated sprain motions at different falling platform orientations $(0,23$, 45,67 , and 90 degrees) on a pair of mechanical sprain simulators [45]. In each trial, the participant stood with his body weight evenly distributed on both platforms, and one of the platforms fell suddenly without prior notice to the participant. Besides, each participant also performed three trials of a manual spraining motion test (Figure 1).

At the start, each participant stood at the anatomical position and was instructed to place more weight on the support leg (Figure 1a). Upon verbal instruction from a research assistant, each participant voluntarily twisted his right ankle joint to their maximum inversion range as fast as possible (Figure 1b). Several practice trials were allowed for each participant until he was familiarised to perform the voluntary twisting motion. This motion was included since it could potentially induce fast ankle-twisting velocity. As body weight was mainly loaded on the support leg, the motion was not hazardous, and no injuries were recorded during the experiment. Each participant was required to verbally report after every trial if that trial was successfully performed to be as fast as possible within his ability, and only trials that achieved this was collected and analysed.

\section{E. Data analysis}

All data were trimmed from 1 second before to 2 seconds after the moment the participant landed on the force plate (for common sporting motions), or the moment of the start of the simulated and manual sprain test as recorded by the gyroscope. The peak twisting velocity collected by the gyroscope and the peak ankle inversion velocity collected by the optical motion analysis system from each participant in each testing condition were extracted. Pearson correlation was performed to show if there is any significant positive correlation between the two parameters. According to a previous study suggesting the strength of correlation in medical studies, a correlation value of $\leq 0.35,0.36$ to 0.67 , and 0.68 to 1.0 was taken as low or weak, modest or moderate, and strong or high correlations respectively [46]. Independent t-tests were conducted to show if there is any significant difference between the two parameters. Statistical significance was set at $\mathrm{p}<0.05$ levels.

\section{REsults}

Pearson test showed a significant positive strong or high correlation between the peak twisting velocity collected by the gyroscope and the peak ankle inversion velocity collected by the optical motion analysis system $(\mathrm{r}=0.693, \mathrm{p}<0.001$, Figure 2). Table 1 showed the mean and standard deviation of the two parameters in each testing condition. The peak twisting velocity collected by the gyroscope ranged from 91.9 to $432.4 \mathrm{deg} / \mathrm{s}$, and the peak ankle inversion velocity collected by the optical motion analysis system ranged from 151.7 to $379.1 \mathrm{deg} / \mathrm{s}$. Independent t-tests showed no significant difference between the two parameters in all testing conditions except the manual twisting test $(\mathrm{p}=0.026)$.

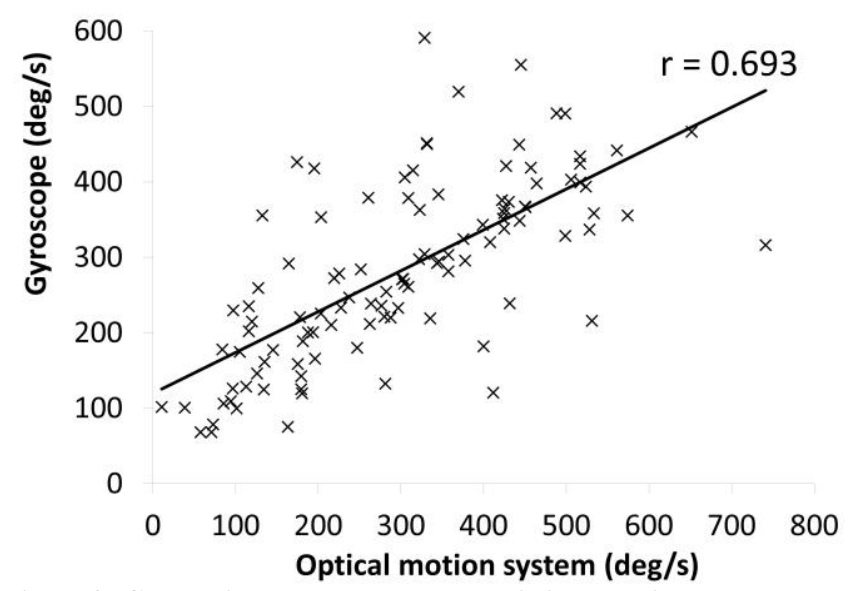

Figure 2: Correlation between the peak twisting velocity collected by the gyroscope and the peak ankle inversion velocity collected by the optical motion analysis system.

Table 1. Peak inversion velocities ( $\mathrm{deg} / \mathrm{s})$ measured by the optical motion analysis and peak twisting velocity $(\mathrm{deg} / \mathrm{s})$ collected by the gyroscope in different testing conditions (mean \pm standard deviation).

\begin{tabular}{lccc}
\hline & $\begin{array}{c}\text { Optical Motion } \\
\text { Analysis (deg/s) }\end{array}$ & Gyroscope (deg/s) & p-value \\
\hline Cutting & $432.4 \pm 151.1$ & $374.8 \pm 100.2$ & 0.384 \\
Jumping & $344.7 \pm 126.3$ & $379.1 \pm 117.8$ & 0.536 \\
Running & $348.7 \pm 125.4$ & $265.0 \pm 96.9$ & 0.157 \\
Step down & $109.2 \pm 31.5$ & $161.0 \pm 93.2$ & 0.115 \\
Walking & $230.2 \pm 109.3$ & $226.5 \pm 84.1$ & 0.940 \\
Simulated sprain, 0。 & $297.5 \pm 41.3$ & $296.0 \pm 92.7$ & 0.969 \\
Simulated sprain, 23。 & $266.6 \pm 44.9$ & $248.1 \pm 26.6$ & 0.367 \\
Simulated sprain, 45。 & $223.9 \pm 78.6$ & $199.1 \pm 21.6$ & 0.437 \\
Simulated sprain, 67。 & $143.2 \pm 72.8$ & $151.7 \pm 52.7$ & 0.808 \\
Simulated sprain, 90。 & $91.9 \pm 73.5$ & $155.4 \pm 77.5$ & 0.141 \\
Manual Twist & $422.7 \pm 83.8$ & $348.3 \pm 58.8$ & $0.026^{*}$ \\
\hline
\end{tabular}

* Significant difference between optical motion analysis and gyroscope $(\mathrm{p}<$ $0.05)$. 


\section{DISCUSSION}

A significant positive strong or high correlation was found between the peak twisting velocity collected by the gyroscope and the peak ankle inversion velocity collected by the optical motion analysis system $(r=0.693, p<0.001)$. This confirmed the first part of the hypothesis, which was a positive linear relationship in between. There was no significant difference between the two parameters in all 5 tested common sporting motions and all 5 simulated sprain motions. This indicated that the second part of the hypothesis was also confirmed in these 10 tested conditions. As there was no difference between the two parameters and there was a significant correlation, the results validated the use of the uniaxial gyroscope in monitoring the peak ankle inversion velocity during these motions.

Based on the results in this study, validation was not achieved in the manual twist test as the two parameters significantly differed from each other. One possible explanation was that the ankle inversion performed in this motion was contributed by both the tilting movement of both the foot and shank segments, but not just the foot segment. The participants performed the movement by swinging the ankle joint complex outwards, and both the shank and foot segments were tilted. Therefore, to record the total range of ankle inversion and also its peak velocity, two motion sensors are needed on the foot and the shank segments. As we only had one sensor on the foot segment, we might have only recorded the range of inversion and its velocity contributed by the rotation of the foot segment only. Our method relies on an assumption that the shank segment is usually upright and does not tilt. This can be applicable in real ankle sprain incidents, the shank movement is usually upright during the whole incident, with mainly the foot segment rotating inward, thus a vigorous ankle inversion movement. Therefore, we believe that the manual twist testing protocol might not be able to truly mimick the scenario of ankle sprain injuries. However, we believe that the results are still practically useful as when the peak twisting velocity recorded by the gyroscope (348.3 \pm $58.8 \mathrm{deg} / \mathrm{s}$ ) was lower than the peak ankle inversion velocity recorded by the optional motion analysis system (422.7 \pm 83.8 ), the value was not too far away as it is $82 \%$ of the value, and the value was also above the suggested threshold 300 $\mathrm{deg} / \mathrm{s}$ from a previous study [37]. Therefore, we believed that when this is used practically for manual twisting like motion, its use is still suitable for detecting the hazard of a lateral ankle sprain.

Another observation was that while the peak ankle inversion velocities in the simulated sprain motions recorded in this study (from 91.9 to $297.5 \mathrm{deg} / \mathrm{s}$ ) were in pretty good agreement to that reported in a previous study (from 114.0 to $202.5 \mathrm{deg} / \mathrm{s}$ ) [37], those in the common sporting motion (from 109.2 to $432.4 \mathrm{deg} / \mathrm{s}$ ) seemed to be a lot higher than that reports in the same previous study (from 22.5 to $85.1 \mathrm{deg} / \mathrm{s}$ ) [37]. One possible explanation could be the nature of the participants, who were athletes in at least one kind of court sports which lateral, sideward, or cutting movements are commonly presented, so they might have performed these sporting motion more vigorously in the laboratory, resulting in higher recorded peak ankle inversion velocities, thus the discrepancy. We believed these higher recorded peak ankle inversion velocities are still substantially lower than that in real ankle sprain injury incidents, as reported as between 481 to $1752 \mathrm{deg} / \mathrm{s}$ [33-36]. Therefore, the use of a single uni-axial gyroscope to detect ankle sprain hazard by monitoring this twisting velocity should still be feasible, but the threshold should be adjustable from about 300 to $500 \mathrm{deg} / \mathrm{s}$ for different users, for examples, runners can have it lower for better protection, and athletes in court sports can have it higher to allow room for faster ankle movement for performance.

The sampling frequency of the gyroscope was $500 \mathrm{~Hz}$, which was much higher than that being used in some previous studies which ranged from 20 to $200 \mathrm{~Hz}[47,48]$. With a 500 $\mathrm{Hz}$ sampling speed, we can obtain one data point per $2 \mathrm{~ms}$. As an ankle sprain injury occurs in $40-50 \mathrm{~ms}$ after foot strike [15,31], the current method allows 20 data points for this peak ankle inversion velocity to be detected. This is adequate for the fast speed of most sporting motions. There is also a room for future study to lower the sampling frequency to save computing power and battery. We believe that it is still feasible to use a $100 \mathrm{~Hz}$ sampling frequency, i.e. $10 \mathrm{~ms}$ per data point, to detect the hazard of lateral ankle sprain feasible.

The data collected by the single uniaxial gyroscope does not represent exactly the ankle inversion kinematics, even if the alignment is perfect. It was the change of the tilting orientation of the sensor concerning the earth. When it was firmly attached to the heel, it measured the change of the tilting orientation of the foot segment. To measure joint ankle kinematics, two sensors are required on the two segments proximal and distal to the joint. We did not place a sensor on the shank segment as we believed including it will make the system practically less feasible, as the user will have to place one more sensor on the lower leg. Now with the single uniaxial gyroscope design on the heel, we have assumed that the shank segment is vertical to the ground most of the time. Therefore, it is possible to use just one sensor on the foot segment that would twist a lot and neglect the orientation of the shank segment.

\section{LIMITATION}

This study has delimited the participants to recreational male athletes only. They must be participating in at least a kind of court sports that involves lateral, sideward, or cutting movements, so if the method presented in this study is feasible on them, likely it is also feasible in other sports with less lateral movement, e.g. jogging. However, we have no information on if this will also work on female athletes who are known to have different foot shape and ankle joint biomechanics, therefore, a validation study on female athletes should be done before the method is employed on them. Finally, as the current study only measured the ankle joint inversion velocity in a laboratory environment, future studies with wireless sensors for field test is recommended to test the validity in clinical settings.

\section{CONCLUSION}

We presented a method to use a single uniaxial gyroscope attached to the heel for detecting the hazard of a lateral ankle 
sprain, based on the peak ankle inversion velocity. The method can be employed as a monitoring system to actuate a correction system that delivers external electrical stimulation to the lateral shank muscles to prevent ankle sprain injury by stopping sudden and vigorous ankle inversion motion.

\section{ACKNOWLEDGMENT}

The authors acknowledged the donation of equipment and resources by The Hong Kong Jockey Club Charities Trust and the funding support from the Innovation and Technology Fund, Innovation and Technology Commission, Hong Kong Special Administrative Region Government (ITS/013/07).

\section{CONFLICT OF INTEREST DECLARATION}

Alan H.F. Lam is the Founder and CEO of Sengital Limited which provided the motion sensors for this study as in-kind support under an approved project granted by the Innovation Technology Fund (Project no: ITS/013/07). He is also a named industrial collaborator in the project team in the said project with the responsibility to provide the software, validation of the device, and resources for this study. Other authors declare no conflict of interest.

\section{REFERENCES}

[1]D.T.P. Fong, Y. Hong, L.K. Chan, P.S.H. Yung, K.M. Chan, "A systematic review on ankle injury and ankle sprain in sports," Sports Med., vol. 37, no. 1, pp. 73-94, 2007.

[2]C. Doherty, E. Delahunt, B. Caulfield, J. Hertel, J. Ryan, C. Bleakley, "The incidence and prevalence of ankle sprain injury: a systematic review and meta-analysis of prospective epidemiological studies," Sports Med., vol. 44, no. 1, pp. 123-140, 2014.

[3]J. Hertel, R.O. Corbett, "An updated model of chronic ankle instability," $J$. Athl. Train., vol. 54, no. 6, pp 572-588, 2019.

[4]K. Jeon, K. Kim, N. Kang, "Leg stiffness control during drop landing movement in individuals with mechanical and functional ankle disabilities," Sports Biomech., DOI. 10.1080/14763141.2020.1726997

[5]T. Lilley, C.C. Herb, J. Hart, J. Hertel, "Lower extremity joint coupling variability during gait in young adults with and without chronic ankle instability," Sports Biomech., vol. 17, no. 2, pp. 261-272, 2018.

[6]P.A. Gribble, C.M. Bleakley, B.M. Caulfield, C.L. Docherty, F. Fourchet, D.T.P. Fong, J. Hertel, C.E. Hiller, T.W. Kaminski, P.O. McKeon, K.M. Refshauge, E.A. Verhagen, B.T. Vicenzino, E.A. Wikstrom, E. Delahunt, "Evidence review for the 2016 International Ankle Consortium consensus statement on the prevalence, impact and longterm consequences of lateral ankle sprains," Br. J. Sports Med., vol. 50, no. 24, pp 1496-1505, 2016.

[7]G. Vuurberg, H. Pereira, L. Blankevoort, C.N. van Dijk, "Anatomic stabilization techniques provide superior results in terms of functional outcome in patients suffering from chronic ankle instability compared to non-anatomic techniques," Knee Surg. Sports Traumatol. Arthrosc., vol. 26, no. 7, pp. 2183-2195, 2018

[8]G.W. Lee, A. Santoso, K.B. Lee, "Comparison of intermediate-term outcomes of total ankle arthroplasty in primary and ligamentous posttraumatic osteoarthritis," Foot Ankle Int., vol. 40, no. 11, pp. 1273-1281, 2019.

[9]P.A. Gribble, C.M. Bleakley, B.M. Caulfield, C.L. Docherty, F. Fourchet, D.T.P. Fong, J. Hertel, C.E. Hiller, T.W. Kaminski, P.O. McKeon, K.M. Refshauge, E.A. Verhagen, B.T. Vicenzino, E.A. Wikstrom, E. Delahunt, "2016 consensus statement of the International Ankle Consortium: prevalence, impact and long-term consequences of lateral ankle sprains," Br. J. Sports Med., vol. 50, no. 24, pp 1493-1495. 2016.

[10] N. Sato, H. Nunome, L.S. Hopper, T. Ikegami, "Ankle taping can reduce external ankle joint moments during drop landings on a tilted surface," Sports Biomech., vol. 18, no. 1, pp. 28-38, 2019.
[11] N. Sato, H. Nunome, M. Hattori, T. Ikegami, T, "Effect of individual ankle taping components on the restriction of ankle external inversion moment," Sports Biomech. DOI. 10.1080/14763141.2020.1792539.

[12] C. Moore, L. Donovan, A.M. Murray, C. Armstrong, N.R. Glaviano, "External ankle taping does not alter lower extremity side-step and straight sprint biomechanics in young adult males," Sports Biomech. Vol. 19, no. 3, pp. 395-410. 2020.

[13] Z.J. Henderson, P. Sanzo, C. Zerpa, D. Kivi, "Ankle bracing's effects during a modified agility task: analysis of sEMG, impulse, and time to complete using a crossover, repeated measures design," Sports Biomech. DOI. 10.1080/14763141.2020.1778777

[14] O.B.A. Owoeye, L.M. Palacios-Derflingher, C.A. Emery, "Prevention of ankle sprain injuries in youth soccer and basketball: effectiveness of a neuromuscular training program and examining risk factors," Clin. J. Sport Med., vol. 28, no. 4, pp. 325-331, 2018.

[15] D.T.P. Fong, Y.Y. Chan, K.M. Mok, P.S.H. Yung, K.M. Chan, "Understanding acute ankle ligamentous sprain injury in sports," Sports Med. Arthrosc. Rehabil. Ther. Technol., vol. 1, pp. 14, 2009.

[16] D.T.P. Fong, W.C. Leung, K.M. Mok, P.S.H. Yung, "Delayed ankle muscle reaction time in female amateur footballers after the first $15 \mathrm{~min}$ of a simulated prolonged football protocol," J. Exp. Orthop., vol. 7, pp. 54,2020

[17] M.L. Cordova, L.W. Bernard, K.K. Au, T.J. Demchak, M.B. Stone, J.M. Sefton, "Cryotherapy and ankle bracing effects on peroneus longus response during sudden inversion," J. Electromyogr. Kinesiol., vol. 20, no. 2, pp. 348-353, 2010.

[18] B. Henry, T. McLoda, C.L. Docherty, J. Schrader, "The effect of plyometric training on peroneal latency," J. Sport Rehabil., vol. 19, no. 3, pp. 288-300, 2010.

[19] C.W. Linford, J.T. Hopkins, S.S. Schulthies, B. Freland, D.O. Draper, I. Hunter, "Effects of neuromuscular training on the reaction time and electromechanical delay of the peroneus longus muscle," Arch. Phys. Med. Rehabil., vol. 87, no, 3, pp. 395-401, 2006.

[20] D.T.P. Fong, "An intelligent sport shoe to prevent ankle inversion sprain injury,” J. Foot Ankle Res., vol. 5, no. Supp 1, pp. K6, 2012.

[21] M. Attia, M.F. Taher, "A wearable device for monitoring and prevention of repetitive ankle sprain," Conf. Proc. IEEE Eng. Med. Biol. Soc., vol. 2015, pp. 4667-4670, 2015.

[22] M. Attia, M.F. Taher, A.R. Youssef, "Design and validation of a smart wearable device to prevent recurrent ankle sprain," J. Med. Eng. Technol., vol. 42, no. 6, pp. 461-467, 2018.

[23] D.T.P. Fong, V.W.S. Chu, K.M. Chan, "Myoelectric stimulation on peroneal muscles resists simulated ankle sprain motion," J. Biomech., vol. 45, no. 11, pp. 2055-2057, 2012

[24] D.T.P. Fong, D. Wang, V.W.S. Chu, K.M. Chan, "Myoelectric stimulation on peroneal muscles with electrodes of the muscle belly size attached to the upper shank gives the best effect in resisting simulated ankle sprain motion," J. Biomech., vol. 46, no. 6, pp. 1088-1091, 2013.

[25] K.L. Kirk, J.T. Campbell, G.P. Guyton, B.G. Parks, L.C. Schon, "ATFL elongation after Brostrom procedure: a biomechanical investigation," Foot Ankle Int., vol. 29, no. 11, pp. 1126-1130, 2008.

[26] D.T.P. Fong, Y.Y. Chan, Y. Hong, P.S.H. Yung, K.Y. Fung, K.M. Chan, "A three-pressure-sensor (3PS) system for monitoring ankle supination torque during sport motions," J. Biomech., vol. 41, no. 11, pp. 25622566, 2008.

[27] D.T.P. Fong, Y.Y. Chan, "The use of wearable inertial motion sensors in human lower limb biomechanics studies - a systematic review," Sensors, vol. 10, no. 12, pp. 11556-11565, 2010.

[28] D.T.W. Fong, J.C.Y. Wong, A.H.F. Lam., R.H.W. Lam, W.J. Li, "A wireless motion sensing system using ADXL MEMS accelerometers for sports science applications," in Proc. $5^{\text {th }}$ WCICA, Hangzhou, China, vol. 6, pp. 5635-5640, 2004.

[29] K.J. O’Donovan, R. Kamnik, D.T. O'Keeffe, G.M. Lyons, “An inertial and magnetic sensor based technique for joint angle measurement," $J$. Biomech., vol. 40, no. 12, pp. 2604-2611. 2007.

[30] Y.Y. Chan, D.T.P. Fong, M.M.L. Chung, W.J. Li, W.H. Liao, P.S.H. Yung, K.M. Chan, "Identification of ankle sprain motion from common sporting activities by dorsal foot kinematics data," J. Biomech., vol 43, no. 10, pp. 1965-1969., 2010.

[31] J.A. Ashton-Miller, R.A. Ottaviani, C. Hutchinson, E.M. Wojtys, "What best protects the inverted weightbearing ankle against further inversion?" Am. J. Sports Med., vol. 24, no. 6, pp. 800-809. 1996.

[32] H.F. Ginz, F. Zorzato, P.A. Iaizzo, A. Urwyler, "Effect of three anaesthetic techniques on isometric skeletal muscle strength," $\mathrm{Br} . J$. Anaesth., vol. 92, no. 3, pp. 367-372, 2004. 
[33] D.T.P. Fong, Y. Hong, Y. Shima, T. Krosshaug, P.S.H. Yung, K.M. Chan, "Biomechanics of supination ankle sprain - a case report of an accidental injury event in the laboratory," Am. J. Sports Med., vol. 37, no. 4, pp. 822-827, 2009.

[34] K.M. Mok, D.T.P. Fong, T. Krosshaug, L. Engebretsen, A.S.L. Hung, P.S.H. Yung, K.M. Chan, "Kinematics analysis of ankle inversion ligamentous sprain injuries in sports -2 cases during the 2008 Beijing Olympics," Am. J. Sports Med., vol. 39, no. 7, pp. 1548-1552, 2011

[35] D.T.P. Fong, S.C.W. Ha, K.M. Mok, C.W.L. Chan, K.M. Chan, "Kinematics analysis of ankle inversion ligamentous sprain injuries in sports - five cases from televised tennis competitions," Am. J. Sports Med., vol. 40, no. 11, pp. 2627-2632, 2012.

[36] E. Panagiotakis, K.M. Mok, D.T.P. Fong, A.M.J. Bull, "Biomechanical analysis of ankle ligamentous sprain injury cases from televised basketball games: understanding when, how and why ligament failure occurs," J. Sci. Med. Sport, vol. 20, no. 12, pp. 1057-1061, 2017.

[37] V.W.S. Chu, D.T.P. Fong, Y.Y. Chan, P.S.H. Yung, K.Y. Fung, K.M. Chan, "Differentiation of ankle sprain motion and common sporting motion by ankle inversion velocity," J. Biomech., vol. 43, no. 10, pp. 2035-2038, 2010

[38] J. Nielsen, T.K. Landauer, "A mathematical model of the finding of usability problems," Proceedings of the INTERACT '93 and CHI '93 Conference on Human Factors in Computing Systems, pp. 206-213, 1993

[39] D.T.P. Fong, Y. Hong, J.X. Li, "Cushioning and lateral stability functions of cloth sport shoes," Sports Biomech., vol. 6, no. 3, pp. 407$417,2007$.

[40] H.J. Woltring, "A Fortran package for generalized, cross-validatory spline smoothing and differentiation," Adv. Eng. Softw., vol. 8, no. 2, pp. 104-113, 1986

[41] E.S. Grood, W.J. Suntay, "A joint coordinate system for the clinical description of three-dimensional motions: application to the knee," $J$. Biomech. Eng., vol. 105, no. 2, pp. 136-144, 1983.

[42] I. Soderkvist, P.A. Wedin, "Determining the movements of the skeleton using well-configured markers," J. Biomech., vol. 26, no. 12, pp. 14731477,1983

[43] K.S. Erer, "Adaptive usage of the butterworth digital filter," J. Biomech., vol. 40, no. 13, pp. 2934-2943, 2007

[44] D.T.P. Fong, Y.Y. Chan, Y. Hong, P.S.H. Yung, K.Y. Fung, K.M. Chan, "Estimating the complete ground reaction forces with pressure insoles in walking," J. Biomech., vol. 41, no. 11, pp. 2597-2601, 2008

[45] Y.Y. Chan, D.T.P. Fong, P.S.H. Yung, K.Y. Fung, K.M. Chan, "A mechanical supination sprain simulator for studying ankle supination sprain kinematics," J. Biomech., vol. 41, no. 11, pp. 2571-2574, 2008

[46] R. Taylor, "Interpretation of the correlation coefficient: a basic review," J. Diagn. Med. Sonogr., vol. 6, no. 1, pp. 35-39, 1990.

[47] E. Bernmark, C. Wiktorin, "A triaxial accelerometer for measuring arm movements," Appl. Ergon., vol. 33, no. 6, pp. 541-547, 2002.

[48] B. Coley, B.M. Jolles, A. Farron, A. Bourgeois, F. Nussbaumer, C. Pichonnaz, K. Aminian, "Outcome evaluation in shoulder surgery using 3D kinematics sensors," Gait Posture, vol. 25, no. 4, pp.523-532, 2007.

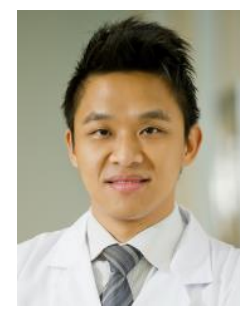

Daniel T.P. Fong received his Ph.D degree in Orthopaedics and Traumatology from The Chinese University of Hong Kong in 2008, with a focus on orthopaedics sports medicine and biomechanics. He was a Research Assistant Professor with the Department of Orthopaedics and Traumatology and the Department of Biomedical Engineering, The Chinese University of Hong Kong, from 2008 to 2013, and a Visiting Scholar with the Department of Orthopaedic Surgery, University of Pittsburgh School of Medicine, in 2012. He is currently a Senior Lecturer of Rehabilitation Science with the National Centre for Sport and Exercise Medicine, School of Sport, Exercise and Health Sciences, Loughborough University, UK. He is also the Director of MSc Musculoskeletal Sport Science and Health programme. His main research expertise is on the mechanism and prevention of sportrelated ankle inversion sprain injury. He is currently the Editor-in-Chief of the Sports Biomechanics Journal. He is a Fellow is The International Society of Biomechanics in Sports (ISBS), Fellow of The Hong Kong Association of Sports Medicine and Sports Science (HKASMSS), and a Life Member of the World Association of Chinese Biomedical Engineers (WACBE).

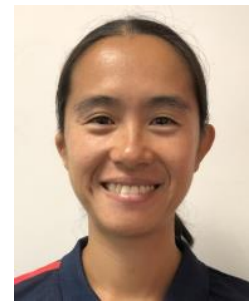

Yue-Yan Chan received her BEng degree in Information Engineering and MPhil degree in Orthopaedics and Traumatology from The Chinese University of Hong Kong in 2006 and 2008 , with a focus on the development of an inshoe motion sensing system to identify ankle sprain motion. She has then served as the manager of Gait Laboratory in Alice Ho Miu Ling Nethersole Hospital, Tai Po, Hong Kong. After several years working in a clinical biomechanics area, she joined the Hong Kong Sports Institute as a Strength and Conditioning Coach, and later a Senior Sports Science Officer. She has published about 10 peer-reviewed articles in orthopaedics, biomechanics, sports medicine, and biomedical engineering areas.

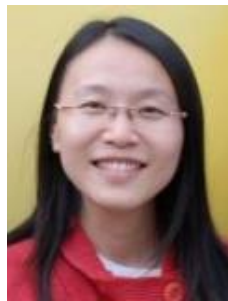

Vikki W.S. Chu received her MPhil in Physics from The Chinese University of Hong Kong in 2002, with a focus on contextual teaching in physical science. She has conducted research in radiocarbon dating of plaster and phytoliths, pretreating bones and charcoal archaeological samples for radiocardon dating with the Kimmel Centre for Archaeological Science, Weizmann Institute of Science, Israel, during 2004-2007. She has then switched to conduct orthopaedic surgery and sports biomechancis study with the Department of Orthopaedics and Traumatology, Prince of Wales Hospital, Faculty of Medicine, The Chinese University of Hong Kong. She has also served as the manager of Gait Laboratory in Alice Ho Miu Ling Nethersole Hospital, Tai Po, New Territories, Hong Kong. She has published about 10 peerreviewed articles in archaeological science, orthopaedics, and sports biomechanics areas.

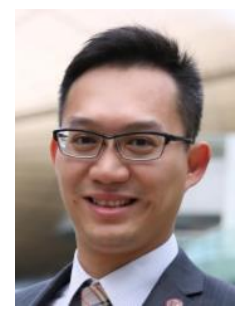

Alan H.F. Lam (M'11) is an Adjunct Professor of the Department of Electrical Engineering, College of Engineering, City University of Hong Kong, and an Adjunct Professor of the Department of Mechanical and Automation Engineering, Faculty of Engineering, The Chinese University of Hong Kong. His main research interest is on Artificial Intelligence, Internet of Things, and the use of wearable motion sensors for sports science and medical applications. He has won numerous prestigious local and international awards for product innovation and excellence. He was named one of the five local innovation heroes by the Hong Kong Science Park in 2014 for his excellence in R\&D projects commercialisation and was selected as one of the awardees of 2015 Hong Kong Ten Outstanding Young Persons.

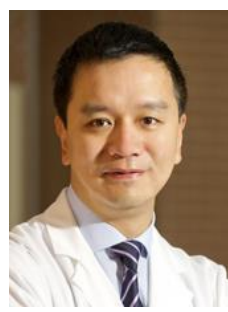

Patrick S.H Yung is currently a Professor and Chairman of Orthopaedics and Traumatology, Faculty of Medicine, The Chinese University of Hong Kong. He is also the directors of various prominent health science centres in Hong Kong, such as The Hong Kong Centre for Sports Medicine and Sports Science, and The Hong Kong Jockey Club Sports Medicine and Health Sciences Centre. He is currently the President of Asian Federation of Sports Medicine (AFSM), as well as the Past President of The Hong Kong Association of Sports Medicine and Sports Science (HKASMSS) and The Hong Kong College of Orthopaedic Surgeons (HKCOS). He has published over 100 peerreviewed journal articles, primarily on orthopaedics and sports medicine. He is currently the Editor-in-Chief of the Asia-Pacific Journal of Sports Medicine, Arthroscopy, Rehabilitation and Technology Journal. He is the Director of two postgraduate MSc programmes, namely MSc Sports Medicine and Health Science, and MSc Musculoskeletal Medicine, Rehabilitation and Geriatric Orthopaedics. $\mathrm{He}$ is the Medical Consultant for the Hong Kong Sports Institute, and the Team Physician of Hong Kong team since 2003. He is an active member of the Elite Anti-Doping and Medical Panel of Asian Football Federation (AFC), as well as the Anti-Doping Disciplinary Panel of the Hong Kong Anti-Doping Committee, Sports Federation and Olympic Committee of Hong Kong. China (SF\&OC). He was one of the awardees of 2009 Hong Kong Ten Outstanding Young Persons. 